\title{
LAWYER COMPETENCIES FOR ACCESS TO JUSTICE: TWO EMPIRICAL STUDIES
}

\author{
Sarah Marsden \\ Sarah Buhler*
}

The definition and framing of legal competencies affects how lawyers learn and enact their roles and forms a necessary site of engagement in evaluating the relationship between law and justice.

Drawing on two community-based studies with members of marginalized communities and lawyers and advocates who work with those communities, we outline the need for a transformation of the idea of legal competencies to emphasize relationality, critical reflection, and deep attention to context. We argue that such a change is a necessary precursor to meaningful engagement with access to justice by the legal profession.

La définition et la formulation des compétences juridiques touchent la façon dont les avocats apprennent et jouent leurs rôles et constituent une première étape obligatoire aux fins de l'évaluation de la relation entre le droit et la justice.

En nous fondant sur deux études menées auprès de membres de collectivités marginalisées ainsi qu'auprès d'avocats et de représentants qui travaillent avec ces personnes, nous expliquons pourquoi il est nécessaire de transformer l'idée des compétences juridiques afin de mettre l'accent sur la relation, sur la réflexion critique et sur l'attention à porter au contexte. Nous affirmons que ce changement est nécessaire pour que les membres de la profession juridique s'engagent de manière significative à améliorer l'accès à la justice.

\section{INTRODUCTION}

In recent years, leaders within the Canadian legal profession have engaged in significant discussions about lawyers' obligations with respect to the access to justice crisis. ${ }^{1}$ At the same time, in the face of growing mobility and other changes within the profession, Canadian legal regulators have sought to define a standardized approach to lawyer competencies: this approach is exemplified by the Federation of Law Societies of Canada's lists of required competencies for graduates of common law programs and

* Sarah Buhler is an Associate Professor at the University of Saskatchewan College of Law. Sarah Marsden is an Assistant Professor at the Thompson Rivers University Faculty of Law. The authors would like to thank the participants in both studies for sharing their time and knowledge, as well as three anonymous peer reviewers for their invaluable feedback. We also express our gratitude to Janelle Anderson, Amanda Dodge, Stan Tu'lnukuafe, and Richard Wong. The fieldwork for these studies was supported by funding from the University of Saskatchewan's President's SSHRC fund and the Thompson Rivers University SSHRC Accelerator fund.

1 See the Canadian Bar Association Access to Justice Committee, Reaching Equal Justice: An Invitation to Envision and Act (Ottawa: Canadian Bar Association, 2013), online: <http://www.cba.org/CBAMediaLibrary/cba_na/images/Equal\%20Justice\%20\%20Microsite/PDFs/EqualJusticeFinalReport-eng.pdf $\geq$; Action Committee on Access to Justice in Civil and Family Matters, Access to Justice in Civil and Family Matters: A Roadmap for Change (October 2013), online $<$ http://www.cfcj-fcjc.org/sites/default/files/docs/2013/AC_Report_English_Final.pdf; Federation of Law Societies of Canada, "Access to Legal Services Initiatives of the Law Societies of Canada" (29 September 2014) online: http://flsc.ca/wp-content/uploads/2014/10/services6.pdf_. 
candidates for bar admission. ${ }^{2}$ Interestingly, the two conversations have rarely overlapped: those discussing lawyers' obligations to enhance access to justice do not typically consider whether lawyers are competent to meet the needs of clients facing access to justice challenges; and those discussing competencies do not tend to consider whether the access to justice crisis demands certain skills or knowledge on the part of lawyers.

Our research, which consists of two separate small-scale qualitative studies undertaken in Saskatchewan and British Columbia, brings these issues together by exploring the competencies required of lawyers working in community legal services contexts. ${ }^{3}$ The first study canvassed the question of lawyer competencies from the perspectives of members and representatives of marginalized communities in Saskatoon, Saskatchewan. The second study consisted of interviews with lawyers and advocates engaged in community-based legal practice in urban and non-urban sites in British Columbia, focusing on traditionally underrepresented communities. Interviews focused on identifying skills, values, and attributes that contribute to successful community lawyering, as well as how success was defined in these contexts.

Based on the responses of our study participants, we elaborate a vision of competences that stands in contrast to mainstream accounts of lawyer competencies. These mainstream accounts (as we discuss below) tend to be characterized by generic, skills-based lists - what we call "the standard checklist". Our goal is not to exchange one set of competencies for another but rather to provide the foundation for an understanding of competencies that is responsive to the actual contexts of practice, with particular emphasis on the contexts in which access to justice shortfalls are most keenly felt. Our research suggests that legal competency demands much more than disaggregated technical skills and knowledge: it requires relationality, critical reflexivity, and deep attention to context.

Our interest in the issue of competencies for legal practice in community legal services contexts is grounded in our experiences as clinical legal educators in urban legal clinics. Through our work in urban legal clinics in Saskatoon and Vancouver, it became evident to us that students deployed skills beyond the standard checklist. For example, the standard skill of "interviewing" can be described simply as extracting the facts from a client's oral narrative. Often, this task is impossible without the deployment of other skills, including professional and tactful communication but perhaps also including the ability to form a relationship with the client, to relate oneself to the client's own community, and to articulate shared understandings, or the lack thereof, with respect and empathy. A large proportion of the Canadian population, including many middle-class people, faces a gap in the ability to obtain legal representation. ${ }^{4}$ However, the brunt of legal services shortfalls is felt within those communities at a greater distance from the legal profession including those living in poverty, those in cultural contexts not well represented or understood within the mainstream of the profession, and those for whom new strategies, like increased technology and online access, are not likely to be functional.

In our experiences in community legal services contexts, clients were often better served when these "other" competencies or "soft skills" were used. For example, where students showed empathy and a basic

2 See Federation of Law Societies of Canada, "Federation Council Approves New Competency Profile" (21 Ocotober 2012), online: <http://flsc.ca/federation-council-approves-new-national-competency-profile/>. This will be discussed in further detail below.

3 For our purposes, we take "community legal services" to mean free, non-profit, frontline legal services provided in particular locations and within specified services mandates. For example, a community legal service provider may be mandated to provide services for members of a specific linguistic or cultural group, or it may simply have the mandate to provide certain legal services for low-income individuals in general. Community legal services providers may receive funding from government or other sources, and they may or may not include opportunities for law students.

4 See Action Committee on Access to Justice in Civil and Family Matters, supra note 1. 
understanding of the clients' backgrounds, this seemed to increase the clients' willingness to trust students with information necessary to the case, to show up for appointments, and to work collaboratively on case strategy. In this example, empathy and sensitivity are not part of the standard checklist, but without them, the capacity to assist is limited. In other words, the difference the clinic made was often not in the numbers served, but by imparting certain qualities to the relationships implicit in legal work. Our research seeks to understand and articulate these qualities in order to provide a baseline for extending our understanding of legal competencies and to better connect these competencies to access to justice in a qualitative sense: to query not only how many people cannot access representation, but also what kind of legal practice will improve access to justice.

By grounding our empirical work in the experiences and observations of people within marginalized communities and those of lawyers and advocates who work directly with such communities, our research invites nuanced and contextual ways of thinking about lawyer competencies in access to justice contexts. This work encourages critical dialogue about legal practice and the interests that are served, or fail to be served, in defining legal competencies. We argue that any change in the assessment of lawyer competencies should aim to improve access to justice, which in our view requires not only adequate state funding and access to lawyers but also a shift in the way lawyers view and enact their roles. In other words, in addition to arguing for specific cultural shifts through how the profession frames competencies, we emphasize that a discussion of access to justice competencies cannot and should not be detached from a broader discussion of public justice infrastructure and properly funded and community-engaged legal aid..$^{5}$ We also believe a rethinking of "legal competencies" is crucial in light of Canada's Truth and Reconciliation Commission's [TRC] Final Report and Calls to Action. The Final Report implicates Canadian law and the legal profession throughout the colonial project, including the application of the doctrine of discovery and the idea of terra nullius, the reserve system, the establishment of residential schools and use of force to compel children's' attendance, the outlawing of Indigenous cultural practices and languages, and the removal of children from homes and communities, racist policing, judicial, incarceration practices, to name only a few. ${ }^{6}$ Calls to Action \#27 and \#28 call specifically on the Federation of Law Societies and on law schools to require lawyers and law students to receive education in the history and legacy of residential schools, international law, treaties, Indigenous law, and Aboriginal Crown relations. In both Calls to Action, the TRC notes that "skills-based training in intercultural competency, conflict resolution, human rights, and anti-racism" will be required to accomplish this. ${ }^{7}$ We believe that meaningfully responding to these Calls to Action requires a major shift in the culture of the legal profession and legal education. Specifically, it is incumbent on the legal profession and on law schools not only to ensure that lawyers and law students learn how to recognize and challenge the ongoing role of law as contributors to colonization, but also to value this type of critical reflective practice as a core competency. In 2016, the Federation of Canadian Law Societies established a working group to respond to the Calls to Action, and committed to providing a national response. ${ }^{8}$ While there does yet appear to

5 For a summary of issues relating to legal aid in Canada, see Melina Buckley, Moving Forward on Legal Aid: Research on Needs and Innovative Approaches, online: Canadian Bar Association $<$ https://www.cfmlawyers.ca/wpcontent/uploads/2012/06/CBA-Legal-Aid-Renewal-Paper.pdf $>$.

6 Truth and Reconciliation Commission of Canada, Final Report (Kingston: McGill-Queen's University Press, 2012) online: $<$ http://www.trc.ca/websites/trcinstitution/index.php?p=890>.

7 Truth and Reconciliation Commission of Canada, Calls to Action (Kingston: McGill-Queen's University Press, 2012) online: <http://www.trc.ca/websites/trcinstitution/File/2015/Findings/Calls_to_Action_English2.pdf $>$ [TRCC, Calls to Action] Number 27.

8 Federation of Canadian Law Societies, News Release, "Federation of Law Societies commits to effective response to TRCC report." (11 March 2016), online: <http://docs.flsc.ca/TRC-March-2016.pdf>. 
be any publicly available material from the working group, we would argue that any such endeavour (and parallel work by provincial law societies) should consider that the definition of competencies may be an important component of a national response.

Thus, in an era where the legal profession is being called upon to address the ongoing crisis in access to justice, ${ }^{9}$ and particularly in light of the Calls to Action of the Truth and Reconciliation Commission, ${ }^{10}$ community practice sites are vitally important in understanding legal competencies and in assessing the adequacy of the profession's existing skills checklists. We propose that in defining competencies, the priority given to particular skills and approaches, the identification of certain skills as mandatory, and the presence or absence of certain skills carries normative weight. In the process of defining competencies, we set out what lawyers must do in order to practice law, but also send a strong message about what does and does not matter to the practice of law.

Furthermore, the framing of a static, universal, and inflexible list of standards itself is problematic we suggest that law and its practitioners must instead be responsive and dynamic in their engagement with the public and all of its communities. The replication of the standard checklist, both in content and in format, tends to reinforce the status quo, in particular as it is based on existing legal practices and practitioners. The current crisis in access to justice is a testament to the fact that the status quo does not serve everyone well, to say the least. Indeed, as described below, lawyers are often viewed with deep skepticism by members of marginalized and underrepresented communities. In our view, then, developing new methods by which to measure and articulate legal competencies is a fundamental component of improving both access to justice and the profession's response to injustices such as those outlined by the Truth and Reconciliation Commission.

This paper proceeds as follows. We first canvas some of the current initiatives and critiques regarding lawyer competencies to provide the context for our research. We then introduce our two empirical studies in turn, discussing research methodology and findings. Following our detailed discussion of our research, we turn to a synthesis of the key findings of the two studies, concluding that lawyering in marginalized communities requires commitments to relationality, deep communication, critical reflexivity and cultural humility. We conclude with some considerations for future research and action in this area.

\section{LEGAL COMPETENCIES IN CANADA: CONTEXTS AND CRITIQUES}

In recent years the issue of lawyer competencies has been top of mind for legal regulators and educators in Canada. In 2012, the Federation of Law Societies of Canada published its "National Entry to Practice Competency Profile" ("the National Profile") for candidates seeking entrance to the legal profession. In addition to basic substantive knowledge, the Profile prescribes what it calls "skills" and "tasks" that prospective lawyers must demonstrate before being admitted to the bar. The National Profile lists mandatory skills in legal research and analysis, communication, practice management, and tasks such as interviewing clients, drafting documents, and using trust conditions. ${ }^{11}$ During this time, the Federation

9 See e.g., Canadian Bar Association, Reaching Equal Justice: An Invitation to Envision and Act (November 2013), online: $<$ http://www.cba.org/CBAMediaLibrary/cba_na/images/Equal\%20Justice\%20\%20Microsite/PDFs/EqualJusticeFinalRe port-eng.pdf $>$.

10 TRCC, Calls to Action, supra note 7.

11 National Admissions Standards Project, National Entry to Practice Competency Profile for Lawyers and Quebec Notaries, (September 2012), online: Federation of Law Societies of Canada $<$ http://flsc.ca/wpcontent/uploads/2014/10/admission4.pdf $>$. The Profile has subsequently been adopted by 13 law societies in Canada on the understanding that adoption is subject to the development and approval of a plan for implementation: see online:

$<\mathrm{http}$ ///flsc.ca/national-initiatives/national-admission-standards/>. 
also adopted a document called the "National Requirement," mandating that Canadian law schools certify that their graduates meet a prescribed set of competencies. The National Requirement includes an enumerated list of skills in the areas of problem solving, legal research and legal communication; an awareness and understanding of ethics and professionalism; and an understanding of the foundations of various areas of substantive law. ${ }^{12}$ Although it is not as detailed and comprehensive as the National Profile (it is directed at law school graduates rather than applicants for admission to the bar), the competencies set out in the National Requirement are broadly consistent with the competencies set out in the National Profile.

We note here that law societies and legal educators have distinct roles, and their interests are not necessarily aligned. Law societies, as regulators, are concerned primarily with the admission of candidates to the legal profession and the licensing and governance of lawyers in practice, including setting standards and discipline of members. The mandate of law schools is to provide a legal education: while graduation from an accredited law program provides a credential sufficient to comply with the admission standards of law societies, law schools are not limited to this narrow function. The extent to which the curriculum and pedagogical priorities of law schools are (or should be) shaped by the mandate of law societies, and the tension generated by pressure on law schools to conform to outside mandates is a subject of considerable debate. ${ }^{13}$ In this article we do not seek to resolve this tension, but propose that the manner in which legal competencies are defined is relevant to law societies, to legal educators, and potentially to the manner in which the relationship between the two is framed. As such, throughout this article we refer to legal regulation and legal education alongside each other.

The Federation undertook a survey of practicing lawyers to validate its list of competencies for the National Profile. ${ }^{14}$ However, the validation methodology is limited in terms of its insights into the function of specific legal competencies or the potential for the definition of competencies to evolve. First, the survey to validate the list of competencies was conducted after the competencies had already been determined. Ex post facto validation can foreclose the potential for comprehensive evaluation of how competencies should be defined, as it presupposes a closed set of answers. Secondly, the survey was limited to practicing lawyers and made no distinction with regard to practice type. ${ }^{15}$ In our view, a robust assessment of competencies must include voices from many participants beyond the profession, and could benefit especially from the inclusion of those whom the law serves, or should serve, and particularly from those communities to which the law is particularly accountable in terms of access to justice and reconciliation. Finally, the validation survey was limited to two questions, specifically how often practicing lawyers use the listed core skills, and the seriousness of the consequence. Lawyers' and clients' interests were listed together in terms of consequences. Skills were considered to be validated if they were frequently used and seen by lawyers as generating consequences if not performed. The survey does show that lawyers use the listed skills and perceive consequences as flowing from certain skills for

12 Federation of Law Societies of Canada, National Requirement, online: $<$ http://docs.flsc.ca/National-RequirementENG.pdf $>$.

13 See e.g., A Rochette \& W Pue, (2001), "Back to Basics? University Legal Education and 21st Century Professionalism" 20 Windsor YB Access Just 167.

14 National Admission Standards Project, National Entry to Practice Competency Profile Validation Survey Report, online: Federation of Law Societies of Canada $<$ http://flsc.ca/wp-content/uploads/2014/10/admission6.pdf $>$.

15 This concern echoes Harry Arthurs' observation that practice-readiness based approaches to competencies in Canada have not been based on empirical research about what lawyers do, or ought to do, when they practice law in increasingly complex and diverse contexts. Harry W Arthurs, "The Future of Law School: Three Visions and a Prediction” (2013) Comparative Research in Law \& Political Economy, Research Paper No 49/2013, online:

$<$ http://digitalcommons.osgoode.yorku.ca/cgi/viewcontent.cgi?article=1291\&context=clpe $\geq$ [Arthurs, "Future"] 
themselves and their clients. However, it does not necessarily validate the Profile's skills listed as a complete set of skills, or even as an empirical identification of priority skills within professional mandates. As it does not consider input from those who receive legal services or otherwise interact with the legal profession, the survey also does not support the claim that its approach to competencies is appropriate to meet the interests of those whom the profession is mandated to serve.

In the United States, the Institute for the Advancement of the American Legal System [IAALS] recently published a report discussing "foundations" for practice, based on a large scale national survey of over 24,000 American lawyers. ${ }^{16}$ Interestingly, the IAALS survey showed that lawyers identified "characteristics" (including "integrity and trustworthiness" and "diligence") as well as "professional competencies" (such as arriving on time and keeping information confidential) as being more important for lawyers entering practice than traditional "legal skills." 17 While certainly large in scope and significant in that respect, the IAALS survey is subject to similar methodological issues as those we pointed out above with respect to the Federation's validation study: it starts with a pregiven definition of competencies and asks lawyers to prioritize them rather than using research to determine how competencies should be defined, drawing on a broad cohort of those whose interests are affected by the practice of law. Furthermore, recent American scholarship has also critiqued the use of self-reporting surveys, arguing that at best they can establish what lawyers say they do. Sinsheimer and Herring's work on lawyers' actual practice both establishes this critique and provides a methodological alternative: their study uses ethnographic fieldwork to understand how lawyers practice. ${ }^{18}$

The Federation's approach to competencies has been the subject of various critiques. Harry Arthurs argues that Canadian law societies take a "fundamentalist" approach to legal practice that "ignores the extent and rapidity of social, cultural, political, and economic change which shortens the shelf life of much substantive law and requires ongoing revision of the institutions and processes through which law works." 19 Similarly, Nathalie Des Rosiers argues that lists of practice competencies compiled by law societies reflect an "essentialist" approach, noting that "the expression by law societies of the essence of lawyering creates the danger of reducing the legal function to its technical component." 20 Certainly, by presenting competencies as though they are neutral and acontextual, the Federation reflects the dominant culture of legal practice: it tends not to identify itself as a culture with specific values. But the legal profession inevitably does reproduce specific values. Emphasizing the technical nature of certain skills does not erase their normative weight, and the political heft of the "technical" should not be underestimated. As American clinical law scholar Phyllis Goldfarb has argued, there is always "a

16 Alli Gerkman \& Logan Cornett, Foundations for Practice: the Whole Lawyer and the Character Quotient, (July 2016) online: Institute for the Advancement of the American Legal System

$<$ http://iaals.du.edu/sites/default/files/reports/foundations_for_practice_whole_lawyer_character_quotient.pdf $>$.

17 Ibid at 3. Also note that Hilary Sommerlad has conducted qualitative research about "quality" in legal aid practice in the British context: Hilary Sommerlad, "English Perspectives on Quality: the Client-Led Model of Quality - A Third Way?" (1999-2000) 33 UBC L Rev 491.

18 Ann Sinsheimer and David J. Herring, "Lawyers at Work: A Study of the Reading, Writing, and Communication Practices of Legal Professionals" (2016) 21 Legal Writing Journal 1, online: LWJ $<\mathrm{http}$ //www.legalwritingjournal.org/2016/11/04/lawyers-at-work-a-study-of-the-reading-writing-and-communicationpractices-of-legal-professionals/>

19 Harry Arthurs, “'Valour Rather than Prudence': Hard Times and Hard Choices for Canada's Legal Academy” (2013) 76 Sask L Rev 73 at 86.

20 Nathalie des Rosiers, "Legal Competencies for the World We Live In", (9 June 2016) online: SLAW

$<$ http://www.slaw.ca/2016/06/09/legal-competencies-for-the-world-we-live-in/>. 
normative perspective... inherent in all lawyering skills." 21 Andrew Goldsmith and David Bamford have similarly argued that practice always has "political, social, economic, and ethical consequences." 22

Further, critics have pointed out that the Federation's generic, one-size-fits-all approach to competencies is focused on the work of lawyers in private and corporate practice, and fails to adequately consider the diverse contexts in which lawyers actually work, and the diverse clients and communities with whom they work. ${ }^{23}$ As noted above, one such context is the community legal services context, wherein lawyers provide legal services to members of economically marginalized or otherwise underrepresented communities.

\section{OUR RESEARCH STUDIES}

In this section, we describe the methodologies and findings of the two studies. We note at the outset that our studies do not create a dataset sufficient to provide sweeping quantitative conclusions; nor were they designed with such an intent. Rather, they investigate a subset of legal practice which is likely to be underrepresented in standard definitions of legal competencies and focused on those communities most affected by access to justice shortfalls. While the studies were limited to participants in Saskatoon and British Columbia, the interview topics are relevant across Canadian jurisdictions, and we hope that our conclusions may be useful in the design of larger scale studies. In placing the British Columbia study in dialogue with the Saskatchewan study, we consider perspectives both from practitioners and recipients of legal services, and in so doing, we assume that the most urgent impacts of access to justice shortfalls are roughly similar between jurisdictions.

While the fieldwork for each of these two studies was designed and undertaken separately, we have chosen to present the results and analysis together for three main reasons. Firstly, we became aware of significant complementarity in our methodological and theoretical approaches. Secondly, given small study cohorts in distinct locations with similar results, we hoped the value of our conclusions would be enriched by joining the reporting and analysis of these studies, particularly as they demonstrate multiple perspectives on the same topic (i.e. those of clients, advocates, and lawyers). Finally, by reporting from these multiple perspectives in a comprehensive manner, we hope to encourage reflection on the value of focusing on input from those served by legal professionals rather than solely from legal professionals themselves. As is evident from the results described below, there are approaches which lawyers and advocates see as effective, but which clients and community members may not. Similarly, clients and community members raise issues which do not appear to be considered by the lawyers and advocates. While the conclusions from this particular duo of studies is limited, we propose that it sheds enough light on the disparity between lawyers and clients' perspectives to justify including the latter as a central component of methodology for future work.

21 Phyllis Goldfarb, “A Theory-Practice Spiral: the Ethics of Feminism and Clinical Legal Education” (1990-1991) 75 Minn L Rev 1599 at 1659.

22 Andrew Goldsmith and David Bamford, "The Value of Practice in Legal Education" in Fiona Cownie, ed, Stakeholders in the Law School (Oxford: Hart Publishing, 2010) 157 at 163-164.

23 See Virgina Galt, Class Wars - Shaking Up the Law School Curriculum, online: CBA National $<$ http://www.nationalmagazine.ca/Members/galtv.aspx $\geq$. See also Robert J. Condlin, “'Practice Ready Graduates': A Millennialist Fantasy" (2014) 31 Touro L Rev 75. 


\section{A. The Saskatoon Study \\ 1. Methodology}

The Saskatoon study sought to understand perceptions of the legal profession held by members of marginalized communities, and to learn from participants what they thought lawyers should do and know in order to work competently in their communities. The project included two main cohorts of respondents. The first was comprised of community members who had direct lived experience of marginalization and interactions with lawyers and the justice system; these respondents participated in individual interviews. The second group was comprised of representatives of community organizations working directly with members of marginalized communities in Saskatoon; these respondents participated in focus group interviews. At least half of the focus group participants identified themselves as having direct lived experience of poverty, racism, and marginalization, which added to the depth and value of their insights. We used a focus group method for representatives of community organizations because, as Brown et al have pointed out, focus groups can "give rise synergistically to insights and solutions that would not come about without them." 24

The first cohort was recruited through postering at community organizations, including friendship centres, food banks, youth centres, Indigenous organizations, and social justice advocacy organizations. Individuals were invited to contact the researcher to arrange an individual interview. The second cohort was recruited through direct email or telephone invitation to community organizations. Questions for both groups were focused on perceptions of law and the legal profession, and perspectives on competent and effective legal practice in the community. The interviews were semi-structured and lasted between 30 minutes and 1.5 hours. We conducted a total of four small focus groups with a total of nine participants, and 12 individual interviews, all in the summer and fall of 2013. A total of 21 people participated in the study. The interviews and focus groups were digitally recorded, transcribed verbatim, and then coded by identifying emergent themes.

\section{Results}

We turn first to a discussion of what participants said about the legal profession: they shared pointed critiques of the legal profession and existing approaches to legal practice. These critiques set the stage for a discussion of the skills, knowledge and characteristics that participants identified as being essential for lawyers seeking to work competently within the community and on behalf of community members.

\section{(a) "Somebody who is just part of the law and not somebody who is on their side": Perspectives on the Legal Profession}

Participants in the Saskatoon study were clear that community members generally do not trust lawyers or consider lawyers to be allies. More than one participant noted that community members are afraid of lawyers. One key reason for this, according to interviewees, is the reality that lawyers are linked inexorably to law and the justice system, which have all too often been sources of harm and oppression within the community. Interviewees pointed out that law and agents of the justice system authorize the removal of children from their families, the over-policing and over-incarceration of family members, and the welfare and housing rules that continually constrain and diminish the life of community members. Because lawyers work with this system and within this system, participants perceived them to be complicit with the harms perpetrated by the system. One participant summed up this view as follows:

24 J Brown, A Collins \& P Duguid, "Situated Cognition and the Culture of Learning" (1989) 18 Educational Researcher 32 at 40 . 
...definitely I would say that [lawyers] wouldn't be someone that [people in the community] would identify with. They would be someone who is, you know, very academic, somebody who is very self-interested, somebody who is just part of the law and not somebody who is on their side.

The same sentiment was shared by another participant who stated: "I think that people feel that lawyers are not on their side because they work with the justice system." Another noted that people in the community "can't fathom how they are going to get justice" within the existing legal system.

Many participants explained that lawyers can be grouped conceptually with other professionals who work within the system, including police, social workers and government officials. One respondent, for example, stated that lawyers are a group "to be scared of," stating: "I think lawyers are still in that same gambit of, like, social services, the institution, the authority." Another participant explained:

So, what do you get when you get someone... who has spent a lifetime of abuse and betrayal and never having anyone on their side. And all of a sudden they are going to walk into a lawyer's office and trust that you are going to do something good for them? So it is a very difficult thing, very very difficult.

She went on to note that "there is that fear and that intimidation around that. Anything to do with Legal Aid, government, police." Another interviewee took a somewhat more nuanced view, explaining that in his opinion, lawyers indeed have a "better reputation than the police officers," noting that, unlike police officers, lawyers "do not have a badge or a sign and they cannot arrest you." This, he felt, made lawyers "safer" than police officers. Several participants referenced specific negative incidents involving lawyers. For example, one woman noted that she knew many people who had been "exploited" by lawyers during the residential school settlement process. She noted that this leads to a general sense in the community that "all white lawyers are bad."

While participants identified lawyers' connections with the dominant justice system as a key barrier to the establishment of trust, they also identified lawyers' disconnection from the community as a problem, in terms of both physical absence from the community and class and race divides. One participant summed up this theme by explaining that lawyers and community members come from "different worlds." One respondent explained that "it's really hard-pressed to find lawyers who walk in at White Buffalo [a local youth centre] at a community event. I think it's hard-pressed to see lawyers walk into the Friendship Inn or the Friendship Centre's community events."

Participants also shared the perception that lawyers too often do not have the interest, the time or the ability to truly connect with their clients, and that this is a further barrier to trust in the legal profession. One participant explained that community members "don't have a lot of relationship with their lawyers." Another noted that people in the community are "looking for connection between themselves and a lawyer. Because they look at lawyers as they are not even human." Another explained that lawyers are "only there to give advice or go to court, they are not there on the sidelines to help," and another stated that "lawyers are just, you know, high-paid businessmen who are, you know, there to fight for the clients or to just get a better deal. And they are not really there to hear what the client really wants."

Several participants expressed an awareness that systemic and institutional factors conspire to keep lawyers inaccessible and disconnected from the community. One identified the "severe" underfunding of legal aid and community legal services. He noted that it is "understandable that you would have a kind of 
puppy-mill approach to legal services, right? Get them in the door and get them out because I've gotten more standing at the door." He explained:

Anything to do with human services is not valued enough. We need to put the money there. It's not - it's that manage and maintain approach that the government has and always will use, right? We'll give you just enough so that there's no uprisings. And, you know, we'll keep you down here for the rest of us to have up here.

While participants shared highly critical views of the legal profession's relationship with marginalized communities, they were clear that lawyers provide definite value to those with power and money, and that the law is skewed to favour people with power. One participant noted that people with money and power "can afford to buy the justice." Another stated that community members "think that the law always goes against them because they don't have the money, they don't have the power." Another explained that "low-income people have a disadvantage. If you have money for a retainer, you could get... sky is the limit."

\section{(b) Community Perspectives on Essential Lawyer Competencies and Knowledge}

The discussion in the previous section showed that participants in the Saskatoon study expressed highly critical views of the legal profession. For them, lawyers are alienated from the concerns and realities of marginalized communities, and are associated instead with a justice system that too often works against the interests of community members. In other words, participants believed that lawyers all too often fail to have the skills and ability to work meaningfully with and on behalf of community members. It is with this larger critique in mind that we turn to the Saskatoon participants' perspectives on essential lawyer competencies. We asked them what lawyers must know and do in order to work effectively in the community. Responses can be grouped into five intersecting themes: (i) the importance of community presence, hospitality and relationality; (ii) understanding of systemic issues and cultural knowledge; (iii) ability to engage in systemic advocacy; (iv) an attitude of humility, respect and compassion; and (v) context-informed listening and communication. Each theme is canvassed in turn.

\section{(i) Community Presence, Hospitality and Relationships}

Participants identified presence in the community, understanding of the community, and the ability to build relationships with the community as crucial for effective lawyering. One participant stated that a "big thing" is for lawyers not to be "scared of the community." She stated, "you need somebody who is going to be in the community. Not in an office, not in a building, but out in the community and talking to the community," because "[y]ou got to know who you're working with." Another respondent stated, "I would like to see more of that, more engaging in the community... I just think there is not enough engagement in the community from lawyers right now." Participants noted the importance of lawyers being "visible out in the community," "being available," "meeting people where they are at," "being where people... need you," and being "open enough to really know the community and love what they are doing."

According to participants, presence in, and relationship with, the community is important for effective lawyering on behalf of community members for several reasons. First, and most importantly, is the issue of trust: presence in the community leads to a building of trust. This is crucial in the face of the pervasive distrust of legal institutions and the legal profession described above. As one participant noted, trust is built up through reputation in the community. She stated, "If I trust you.. then [other community 
members'] know it's okay to talk to you. Because we've established relationships." Participants noted that lawyers who spend time connecting with the community and being present in the community will gain "comfort" and knowledge that will assist them in being effective advocates. They were clear that lawyers who spend time in the community learn about the resources, networks, and connections in the community that clients can draw on, noting that this knowledge can bolster the ability of lawyers to advocate for clients in legal fora. ${ }^{25}$

In a related vein, participants also stressed the importance of lawyers making their services welcoming, comfortable, safe, and accessible to community members. One suggested that lawyers could provide food as a "good initial engagement tool." Another noted that lawyers should be accessible beyond just "9-5." Another cautioned about being too "institutionalized - if everything is too laid out in a business form, it scares people too... Institutionalization affects a lot of people. You get that thought in your head and without thinking, it becomes a barrier for you."

\section{(ii) Understanding of Systemic Issues and Cultural Knowledge}

Participants noted that lawyers must have a sophisticated understanding of the operation of privilege, power, and racism in society. ${ }^{26}$ In Saskatchewan, this requires a specific understanding of the operation of colonialism and its connection with the legal system. As one participant noted, it is problematic when lawyers do not "understand any of that social context, [or] ... get the whole colonization piece." Another stated that lawyers "should receive a lot of training around privilege and power." Participants explained that lawyers must learn about how the legal system works in concert with other oppressive systems to "create hardship," and should also have understanding of poverty, homelessness, addictions, mental health issues, and the impacts of social exclusion, and how all of these issues relate to law and the operation of the justice system. One participant expressed the view that the law school curriculum should include an emphasis on "history,... systemic discrimination... [and] the impact that Residential schools had on family structures." She also suggested a "boot camp" for lawyers that would cover "super basic things that people who have lived a privileged life would not get. So, like, not having a phone number, or not having a place to live, not having food... the realities of people who live in poverty." Several participants were clear that this does not require lawyers to "know everything about everything," or to become "my psychologist or my addictions counselor or any of those other things." However, the majority of participants who addressed this issue were clear that lawyers need better understanding of these systemic issues and how they interact with law.

Participants noted that lawyers seeking to work competently in the community must also clearly be knowledgeable in Indigenous history and culture. This would involve learning from Elders in the community who can act, in the words of one participant, as a "lifeline to understanding the heart process,

25 Participants' observations were consistent with themes from the critical lawyering and community lawyering literature. For example, Gerald Lopez has written about the importance for community lawyers of solidarity and communitybuilding, and the importance for lawyers to act in a "holistic, client-centred manner that is responsive to the community's needs, desires, and perspectives." Gerald Lopez, "Shaping Community Problem Solving around Community Knowledge" (2004) 79 NYU L Rev 59 at 72 . Lopez notes that lawyers are not experts in the issues in the community but rather must be committed to mutuality and reciprocity: Gerald P Lopez, Rebellious Lawyering: One Chicano's View of Progressive Legal Practice (Boulder: Westview Press, 1991) at 37. Similarly, Nancy Cook has emphasized the importance of "presence" and relationship in community-based lawyering in her scholarship: Nancy Cook, "Looking for Justice on a Two-Way Street" (2006) 20 Wash UJL \& Pol'y 269.

26 This theme from the interviews and focus groups resonates with the emphasis in community lawyering literature on the importance for lawyers of examining and being conversant with the root causes of injustice in communities that lead people to interactions with the legal system. See e.g. Artika R Tyner, "Planting People, Growing Justice: the Three Pillars of New Social Justice Lawyering" (2013) 10 Hastings LJ 219 at 224. 
the issues, the traditional healings, and what is important to Aboriginal people." This participant also noted that lawyers working in the community should, if possible, seek to integrate Elders into their work with clients. $^{27}$

\section{(iii) Ability to Engage in Systemic Advocacy}

The systemic knowledge described in the previous section is foundational and helps equip lawyers to engage in systemic advocacy, which several participants identified as an important competency for lawyers working in the community. As one participant noted, lawyers need to be prepared to address issues that may be "outside of the explicit limits of the legal system, but [that are] within the realm of the needs of both the community and an individual within the community." Another explained that lawyers who actually wish to be "effective in the community" would:

have to go beyond the capacity of the legal system to be beneficial and get involved with the community in the ways in which the legal system actually works against the community. They have to address the contradictions within the legal system in their practice in order to be of benefit to the community.

One participant noted that this requires lawyers to be willing to take a stand on social justice issues affecting the community: she questioned why more lawyers had not been involved in recent activism for refugees, querying whether it was because lawyers "don't know, don't care?" Again, these observations call to mind the work of scholars such as Gerald Lopez, who wrote that community lawyers should "work to dismantle unjust social structures" with communities and allies.

For other participants, lawyers need to take a systemic and holistic approach to their work with individual clients, to be willing to "walk with" clients. This involves working and collaborating with other professionals or community organizations to support the client. In the words of a focus group participant:

lawyers have to be involved not only in the law, they have to be part of the plan of recovery or the plan of prison or the plan of getting out of prison. I don't think their job is done when the sentence has been handed down. Again, I don't know if that could be possible that it could be ever done, you know.

\section{(iv) "The Humanness of it": Humility, Respect, and Compassion}

Humility, respect, and compassion emerged through the study as essential attitudes for competent lawyers. All of these attitudes can be grouped together in what one respondent termed "humanness." With respect to the role of humility, one participant explained that lawyers needed to "not sit above" members of the community. Another explained that because people in the community have "been pushed down [by] that authoritative action all the time, whether it's by the police [or] by social services taking their children," it is important for lawyers to "come to a common ground and say, "you know what? I'm not better than you. I'm the same person as you and here is where we are. So, let's see where we can go from here."'

27 Responses align with the work of many critical scholars working in the area of cultural competency. For example, Andrea Curcio and her co-authors have noted that "cultural sensibility" requires "self-awareness of the lawyer's own cultural lens; the ability to understand the cultural forces that affect the lawyer and all those with whom the lawyer communicates; the ability to identify the interaction of those cultural forces; and openness to changing one's perspective based upon what has been learned": AA Curcio, TE Ward \& N Dogra, "Educating Culturally Sensible Lawyers: A Study of Student Attitudes about the Role Culture Plays in Lawyering Process" (2012) 16 UW Sydney L Rev 98 at 100. 
Another participant noted the importance of "just, you know, being a person informed of the problems and just being... not too haughty about, you know, the words and stuff like that. Just being, like, a people person." Another explained that lawyers must stay humble:

So a lawyer in the community, especially this community where it's hard, it's cold, it's miserable, there's problems... just has to have an open personality, of dressing to the community, um... not being a photo op.

Several participants identified the importance of respect by lawyers for their clients, and particularly respect for the agency of their clients. This requires a non-paternalistic approach to practice and a commitment to empowerment. Participants also identified compassion, care, and empathy as essential attitudes for lawyers. One focus group participant explained:

I would love to just be able to see everyone from prosecutors to judges to doctors to nurses, you know, see the reality of Saskatoon and see the reality of society from all viewpoints and be able to just transplant themselves for little pieces of time into other people's shoes and be able to see through their eyes.

Another participant explained that lawyers must be able to respond compassionately and appropriately to the trauma experienced by clients. She explained:

If a lawyer responds by saying "I'm sorry that this is emotional, but we have to deal with the law. We can't deal with your emotion." And it's hard for [the client] to differentiate... And so that's when they are taken aback and go, "Okay, well, the lawyer doesn't care because he just wants the point form and I can't give it to him point form because that's just not how I work. We are speaking a different language."

Another participant stressed the importance of lawyers bringing "some humanness back" and showing "some compassion and thinking... that it's just not a file to get through," but a human being. One respondent summed this theme up as follows: "I really think that that could be almost a cure-all... if they were just able to put humanness back into the people they are dealing with, it would solve so many problems and issues."

According to participants, humility, respect, and compassion are important not only for moral reasons. Rather, participants understood that such attitudes were essential for effective advocacy by lawyers. Given the prevailing negative view in the community, community members will not feel comfortable sharing information with lawyers who are not compassionate, respectful, and open. One participant explained that if faced with a lawyer who is not displaying these attitudes, "I probably would have just sat here and said not a god damn word or pretend I was ignorant." She explained "that's where a lawyer's got to get in their head to really help them. It's more than law."

\section{(v) Deep and Context-informed Listening and Clear Communication}

Participants emphasized that listening and communication skills were essential competencies for lawyers. For most participants, effective listening and communication are not merely technical skills but rather are predicated on compassion, respect, and a willingness to take time with the client. Effective listening also demands a nuanced attention to context, culture, and history, which requires lawyers to draw on knowledge about the impacts of systemic racism and colonialism as discussed above. In this way, the 
"human" attitudes outlined in the previous section are foundational. As one focus group participant explained, effective listening requires that the lawyer be able to "grasp the history" of his or her client. Another participant similarly explained that true listening involves going beyond what the client says and working to understand the "whole story" beyond the immediately relevant "facts." This participant explained:

Do you really hear the whole story? It might be that you're just dealing with the one, we'll say a breach, dealing with that and you need the facts, but what about the other things that are happening in that person's life?... So, you don't really get to the root of the problem.

Similarly, another participant explained that lawyers must get to "know more about the person" and be able to go beyond just the immediate issue at hand.

Listening, according to participants, requires an "ability to engage," "pull out the strengths," and get "into the meat of the issues," which allows the lawyer to advocate effectively for the client. A focus group participant noted that professionals who:

take the time to listen and seem to be able to draw out the strengths and not focus on the negatives do better and have a better rapport with the client... And even if the outcome isn't as advantageous as it could be, having that relationship still leaves the client with the sense that everything has been done or that they have been listened to, which psychologically and emotionally just seems to have a lot more benefit.

Another explained that lawyers who take the time to explain processes clearly to their clients "shows that they really care."

\section{B. The British Columbia Study 1. Methodology}

The initial recruitment poster for the British Columbia study called for lawyers who were involved in community-based practice and was distributed through existing social justice and advocacy lists. Participants were approached based on a balance between urban and non-urban community practitioners and representation from multiple regions in British Columbia as well as a mix of experience levels and communities served. During the recruitment process, it became clear that non-lawyer advocates were responsible for a significant portion of community legal services, particularly in the non-urban regions of British Columbia, and the study cohort was therefore opened to include these individuals as well. The study used semi-structured interviews of one - two hours. A total of 10 participants were interviewed. Because the first 10 respondents met the study criteria, no respondents were excluded in the cohort.

Of the 10 lawyer and advocate participants, there were nine women and one man. Five were practicing lawyers, and five were legal advocates who were not practicing lawyers (although some did have a law degree or other legal training). Two of 10 participants identified themselves as Indigenous. One participant worked as a private practice lawyer, and the other nine worked for non-profit organizations or educational institutions. Four participants were senior practitioners with 10 or more years of experience, three were mid-level with five to 10 years of experience, and three were junior, with less than five years of experience.

Transcriptions were coded thematically, based initially on primary interview topics, namely: defining the client and community base (e.g. who does your practice serve?), defining the practice (e.g. what are the tasks that make up your day?), identifying key traits (e.g. what traits are important for this job), and 
establishing the pedagogical origin of these traits (e.g. where did you learn this trait?). We specifically did not distinguish between "skills" and "characteristics" so as to avoid embedding the binary of ostensibly "learnable" and "innate" features into the study, and to ensure that respondents were not discouraged from reporting values-based, affective, or other types of learning beyond standard law school pedagogy. The interview also asked participants to relate their work to access to justice.

\section{Results}

All participants identified themselves as "community-based" practitioners, and in interviews they described the communities and individuals they served. Unsurprisingly, the communities served were by and large consistent with groups that tend to be marginalized socio-economically, and those that have been on the receiving end of law's colonial and patriarchal legacy, as well as being under-represented in the legal profession. Specifically, the study participants worked primarily with women, Indigenous people, low-income people (including low-wage workers), people with disabilities (including physical, mental, visible, and invisible disabilities), and elders and seniors. Most respondents described communities served using more than one of these labels, and for those respondents working in non-profit organizations, the communities served were also defined in terms of the specific mandate of the organization or its funders.

Participants also defined communities served based on shared experience, including shared experience of the legal system and in broader society. For example, one respondent described the people she worked with as "women who have experienced violence in their lifetime and been impacted by that. Many women impacted by colonization, the inter-generational impacts of that. Women without any family support and limited community support, and women with pretty significant health issues." Shared experience of the legal system was also a basis for defining community, for example: "Most of my clients are on some form of assistance, whether it's income assistance, employment assistance... " or "people that are navigating the child welfare system, navigating the hospital system, entering or exiting out of prison."

After identifying the basic tasks that made up their work, participants answered an open question about the traits that they thought made them good at the work, and, for more senior practitioners, the traits that they thought were important for more junior people in the work. Where participants spoke of such traits outside of this question, they have also been included here. They are arranged here in order of prevalence in participant responses.

\section{(a) Self-reflection and Humility}

Community-based lawyers and advocates emphasized the importance of self-reflection for practitioners - in the words of one respondent:

we take it very seriously that people are doing their own self-exploration, their own empowerment, recognizing their own triggers, their own biases, their own trauma when they're working with people in this field, because there are so many triggers and blindsides that we have as individuals.

While reflective practice has been recognized in the legal field, its place in legal learning is likely to be viewed as marginal or optional, in contrast to disciplines such as social work, in which critical selfreflection is central to learning and practice. ${ }^{28}$ Self-reflection is also likely to contribute to the capacity to

28 See e.g. C Knott \& T Scragg, eds, Reflective Practice in Social Work (London: Sage, 2013), G Ruch, (2002) "From triangle to spiral: Reflective practice in social work education, practice, and research." (2002) 21:2 Social Work Education 199. 
understand one's own cultural perspective and related biases, an essential component of engaging in intercultural and anti-racist lawyering. In the field of psychology, Patricia Devine and her colleagues present a compelling, research-based model of intervention for implicit racial bias that relies on the ability to be aware of and actively resist and reshape stereotypical thinking as well as the capacity to understand the perspective of others. ${ }^{29} \mathrm{In}$ the legal context, this would require the capacity for self-reflection.

Actively resisting paternalism was also raised as an aspect of listening well:

Part of being empathetic would be that you can also listen well and listen like... It's not just listening. It's being able to listen and give feedback and meaningful feedback on what you're hearing. Engaging with people in the conversation in a non-judgmental, nonpaternalistic way or... treating someone like an adult, right?

These responses resonate with critical scholarship on "regnant" lawyering as well as empirical interviewing studies, in which clients' agency and perspectives are often lost in standard legal interviewing modality. ${ }^{30}$ One respondent put it bluntly: "just learning humility and learning how to shut up and listen and yeah... it's humility, humility, humility."

\section{(b) Openness, Empathy, and Non-judgmental Communication}

Many of the respondents also emphasized the importance of openness to clients' experience, particularly through the use of empathy and non-judgmental language. Listening well was a key component of this - and lawyers, even those consciously engaged in working to challenge social inequality, can fail to listen by virtue of their rush to identify relevant facts and to place client experiences into known categories. A participant described her approach as follows: "we' re just trying to meet people where they're at and hear as much as we can in order to properly frame what we're saying, so it's not coming from our analysis alone but actually from people who are encountering these barriers."

Maintaining boundaries can also be a way of respecting a person's agency and understanding the limitations of an advocacy role:

Good boundaries are super important for me. Sort of recognizing that the person sitting across from me, this is their life and this is their issue. I'm not responsible for them or for fixing their problem. So, I can hear what's going on, I can talk to them about what I know, I can share options, I can give them options, but it's their choice, ultimately, what they want to do.

Another lawyer noted the importance of awareness of the impact of questioning styles:

We're often taught that...you're supposed to ask a lot of questions and get the information you need. You know, you excavate your mind for what you need to do your job and that is an incredibly invasive process. So, I think, to not do that, to be perceptively engaged with

29 PG Devine et al, "Long-term reduction in implicit race bias: A prejudice-habit breaking intervention" (2012) $48 \mathrm{~J}$ Experimental Soc Psych 1267 at 1270.

30 See e.g., Gay Gellhorn, "Law and Language: An Empirically-Based Model for the Opening Moments of Client Interviews" (1997) 4 Clinical L Rev 321. 
a person, and it goes beyond listening. It's giving them cues through body language to continue speaking to indicate to them that you're open to hearing their story without asking a lot of questions because that process of interrogation is really off-putting for people and in a lot of cases makes them shut down. So I think that that's a key competency as well.

Non-judgmental listening was highlighted by multiple respondents, but one practitioner distinguished a non-judgmental approach from the task of evaluating the factual basis of clients' statements:

I really work on being non-judgmental, and one of the things that I think is... How do I put it... ? I'm trying to think how to articulate this exactly right. I think that remaining nonjudgmental and allowing your client to have the space to talk about what's going on for them and what's important to them without being judged is really important, and I kind of distinguish that from believing everything that my clients say, because I actually... I'm not somebody who believes everything that my clients say.

One practitioner contrasted empathetic listening with lawyer apathy:

I think that being able to... honour the person, make them feel that their story is important and it's their story, because what ends up happening a lot of the times is that a lot of people [lawyers] that I've seen have become a little bit apathetic and then it's like the client feels... The client needs to feel a sense of safety with you.

The importance of immediate client feedback was echoed by a second practitioner as he described measuring his own success in communicating:

Well if a client is closed and shut down and not really responsive and then by the end of our meeting that has changed, then I know I've managed to at least break through whatever barrier there might have been from their side of things.

\section{(c) Understanding the Context}

Good listening and interviewing may require not only hearing the context of "relevant facts" but reevaluating how context is legally relevant:

Because the students talk a lot about when they come in here about sort of stripped-down fact patterns and things for classes and cases and the sort of reducing of situations to fact patterns. And I think one of the things that we have started working on is putting the context back because it's actually important legally to put it back in.

One respondent noted that having shared lived experience (i.e. shared understandings or experience between lawyer/advocate and client) was also useful to communication.

An advocate talked about the requirement of understanding the impact of colonization within an individual client relationship:

These are my families and friends and so I get, as much as a white person can ever get, I get a lot of some of kind of the challenges that are faced by people trying to deal with governmental systems, whether it's an... Like I don't discount them or minimize them so 
they'll just come in with a letter from the government that they haven't even opened because it scares them, but I know it's simply some kind of weird accounting from Canada Revenue, you know? So I literally sometimes will physically open the letter for them because it's scary for them to do that, right? And I get why. They're survivors, residential school survivors, and they've known nothing good from the government.

She elaborated on the use of cultural translation for legal documents:

Or I've got another friend who's a young Elder who... She's totally capable and intelligent and literate and she's a riot, a writer and a poet and stuff, but she gets a government letter from the pension people most recently and she's like I don't understand this can you look at it like a white person and tell me what it says kind of thing.

\section{(d) Relationality and Relationship-Building}

As is the case with communication, the notion that relationships are important is not novel in considering lawyer competencies. The lawyer-client relationship, in particular, is emphasized in ethics training and mainstream understandings of lawyer competencies. However, study participants elaborate a concept of relationships perhaps better understood as "relationality," as much of their input describes an orientation to practice rather than emphasizing a particular relationship between two individuals. In speaking about how they did their jobs, multiple respondents described their life in the community where they worked, including family relationships, raising their children there, and long-term relationships within the community beyond client-based interactions. They spoke of the continuous work of building relationships with community organizations and educational and government institutions (even when adverse in interest) and assessing whether they had established good relationships through feedback from community members. This competency is closely connected to others: Participants frequently referred to relationship-building with clients as the purpose of communication and as the result of listening well and providing non-judgmental support as well as recognizing power dynamics and refusing paternalism.

Several also mentioned peer and mentorship relationships as essential to their ongoing practice and the importance of building good relationships into organizational practices. Indigenous and non-Indigenous respondents ascribed more relational approaches to Indigenous communities and value systems. As one respondent put it: "the relationship holds more weight than the credentials in a person."

However, another respondent highlighted the need to displace cynical assumptions about client narratives:

I also ask them to approach their clients from a place of trust rather than... A lot of lawyers, that I've worked with anyways, over the short time that I've been in practice have said, "Never believe your client, never believe your client." [In law school] you have to do everything from a place of cynicism and skepticism, and I ask my students not to do that.

\section{(e) Values and Critical Analysis}

When asked about the motivation for the type of practice they pursued, community-based lawyers and advocates spoke about the types of values and analysis that motivated them in their work. Many mentioned equality:

I think that I feel ethically aligned with the work that I do, so I feel like as a feminist, identifying as Indigenous, as someone who believes in substantive equality, in an anti- 
oppressive framework that this is work that I want to be doing and contributing to and work that matters.

I mean, they're all just issues that I've felt very strongly about for a long time, the systemic contributors to placing people in poverty and entrenching that poverty... It's just commitment to this other very principled level of all the intersecting factors that create poverty here in $\mathrm{BC}$ especially just because it's such a wealthy province and it's so unequal.

Multiple practitioners found that a critical analysis of the role of law was important in their communitybased practice, or in the words of one advocate: "not necessarily accepting the status quo of law as a good baseline or starting point." Another framed law as potentially instrumental to, but separate from, justice:

I had no delusions about the ability of the law to create justice, and yet at the same time I knew that there was power in being able to manipulate, or at least at the very nicest, utilize the systems of law to help gain justice.

For some respondents, law school and the profession seemed to entrench values at odds with the values inherent in community-based practice:

For me, the point of going to law school is justice doing. And justice doing, to me, is within a framework of substantive equality. We're uplifting people who are marginalized. And when I went to law school, it was a lot about firm-sponsored beer-ups and this lifestyle that attaches to firms with, you know, you get all this swag and you're going to be driving a nice car and you're going to have this nice office and all these things and that's supposed to be important or what you're striving for.

Another participant commented on the role of the legal profession and law societies, noting that:

there's a lot of material about being a sole practitioner out there, but how much of it is really geared to attracting the right clients and making sure that you get paid and avoiding problem clients and avoiding difficult clients and I kind of always read it feeling like... It's really good advice from a running a small business point of view, it's kind of shitty advice if that's what everybody is following for all of those clients who don't have money and don't have health and aren't attractive and aren't easy to work with... There's very little that I take away from my interactions with the legal profession which makes me think that there's any genuine move... within the profession as a whole to remedy that, or to accept responsibility for that in any way.

\section{CONCLUSIONS AND RECOMMENDATIONS}

We do not purport to offer a prescription to cure the deficiencies of, nor do we wish to replace, existing checklists with new ones under the banner of access to justice. Based on the information shared in these two community-based studies, however, we offer some initial thoughts toward the cultural shift we see as necessary to linking legal competencies with meaningful access to justice practice. There are areas of overlap between the responses of community members in the Saskatoon study and the lawyers and advocates in the British Columbia study, but there are also gaps: both provide potent sites of inquiry and 
insight. Based on the interaction between the two studies presented here, we suggest three main areas in which the understanding of legal competencies can work toward meaningful change.

\section{A. Relationships}

Every relationship has a history which informs its present context; every relationship exists in a web of other relationships, which have histories that interact in complex ways and are conveyed through individuals, institutions, and cultures. Standard conceptions of skills-based competencies, and even those which go beyond the "nuts and bolts" of law to traits like honesty or dependability, tend to focus on individual development, or at the most expansive, the lawyer-client dyad. ${ }^{31}$

We propose a move from a focus on individual, dyadic relationships to the idea of approaching law relationally in a larger sense. Beyond requiring an understanding of ethical minimums for individual relationships, competency requires both an understanding of the centrality of accountable relationships with communities, peers, and institutions. It also requires the capacity to establish and maintain constructive, respectful, long-term relationships, including in adversarial situations or those in which colonial and other power-based relations are present. The very core of a lawyer's duty - representing another person's interests - cannot be undertaken competently without a relationship of trust and recognition, and these are the very features which community members report as lacking in their interactions with lawyers. Both relationship-building and learning to view the world relationally could be integrated as fundamental competencies for lawyers. The specifics will, by necessity, vary, but some of the examples given by study participants in both cohorts increase relationship building directly, such as bringing food, being physically present in a community, and getting to know people in situations beyond specific legal issues and over longer periods of time, to build trust.

Lawyers and advocates also emphasized the value of long-term relationships in their practice. Both study cohorts indicated a need for lawyers to understand specific community histories, including the multigenerational impacts of colonization. Education in Indigenous-settler relations already forms a part of the Calls to Action articulated by the Truth and Reconciliation Commission and is directed at the legal profession. We suggest that emphasizing an understanding of complex relationships as the context for any legal work, as well as relationship-building capacity, could contribute to a substantive response to these Calls.

\section{B. Communication}

Basic communication skills are named, or at least implied, by minimum standards for Canadian legal practice (for example, "eliciting information" and "communicating the law" are considered part of the core communication skills by the Federation). In their responses, study participants not only emphasized the importance of communication, but illuminated the ways in which communication became effective in community-based practice. Participant responses provide rich descriptions which outline not only the need for communication, but the necessary components of good communication in serving underrepresented communities. Given particularly the Truth and Reconciliation Commission's Calls to Action aimed at law schools and law societies, in which it asks both types of institutions to provide "skills-based training in intercultural competency, conflict resolution, human rights, and anti-racism," ${ }^{32}$ we argue that the profession will benefit not only from increased emphasis on lawyers' capacity to communicate, but also in pursuing a more nuanced understanding of the content of "communication skills" and the ways in which

31 See Muneer I Ahmad's critique of the "fetishized" lawyer-client dyad in his article "Interpreting Communities: Lawyering Across Language Difference" (2006-2007) 54 UCLA L Rev 999 at 1074 and 1076-1078.

32 TRCC, Calls to Action, supra note 7, Number 27 
this might relate to equality and access to justice. These studies document multiple qualitative aspects of communication which were emphasized by community-based participants but which tend to be overlooked in conventional understandings of minimum communication skills.

It is no revelation to state that communication with clients is essential in the measurement of legal competencies: any skills checklist for lawyers will include communication explicitly or through listing specific skills which deploy communication, such as interviewing and advising. In terms of assessing the adequacy of communication by lawyers, current skills checklists often use general qualifiers. In the National Competency Profile, for example, a competent lawyer must use "language suitable to the purpose of the communication" and must "advocate[e] in a manner appropriate to the legal and factual context." 33 While none of these are at odds with the data from communities and practitioners, they could be improved by emphasizing particular forms of communication likely to be useful in the context of legal practice that aims to improve access to justice.

These study data underscore not only the relevance of communication as a foundation of legal practice, but more importantly, they provide some guidance in terms of precursors to good communication and traits associated with "appropriate" or "suitable" in community lawyering contexts, which contributes to a qualitative approach to access to justice. In other words, if we start to know how community-based advocates are failing or succeeding in communication, we can move this knowledge and associated strategies from the margins to the centre of practice and teaching.

Jane Aiken proposes the concept of justice-readiness as an alternative to practice-readiness as a goal for legal educators. She defines justice-readiness as having two main components: the ability to identify injustice and the capacity to work toward remedying injustice. ${ }^{34}$ While Aiken uses the idea of justicereadiness to examine the role and duty of clinical education in particular, we find it useful to describe the aim of redefining lawyer competencies at large to better integrate responses to access to justice problems. On the basis of our data, good communication suitable to the practice of justice-ready lawyering requires law students and lawyers to be to be trained in critical self-reflection, literacy in implicit bias, understanding of dominant lawyering culture and its basis in Euro-settler ${ }^{35}$ values, analysis of the role of power in interactions across difference (including concepts of agency, empowerment, and boundaries), and awareness of the relevance of lived context in factual and legal analysis. We also propose that recognition of a variety of economic, social, and cultural environments be explicitly valued as an aspect of communication through active diversification of law schools, encouragement of the use of shared knowledge and experience where it does exist, and exposure to new perspectives through direct experience. Furthermore, the importance of listening was emphasized by participants, but its nuances are minimized in standard understandings of legal competency. Lawyers are trained to listen for "facts" and to exclude what is irrelevant, and we already know that this can mean missing key information and disempowering clients. ${ }^{36}$ Competent lawyers not only need to be empathetic and non-judgmental listeners, but they need to learn to value listening in terms of its potential to recognize and resist regnant lawyering models. ${ }^{37}$ Competency therefore requires an understanding that lawyers are never simply "mining for

National Admissions Standards Project, supra note 11 at 2-3.

J Aiken, "The Clinical Mission of Justice Readiness" (2012) 32:2 Boston College JL \& Soc Just 231 at 233.

We use the term "Euro-settler" to refer to social and cultural practices and values associated with the colonization of North America by European settlers, including ongoing practices of displacement and violence in favour of domination and benefit by those settlers and their descendants. In particular, we understand Canadian legal systems as inextricable from the practice of colonization.

36 Gellhorn, supra note 30.

37 Ahmad, supra note 31. 
facts" and "communicating the law;" rather, in speaking and listening, lawyers convey a broad array of implications about their roles, the place of the client, and the nature of their work.

\section{Values, Critical Reflexivity, and Cultural Humility}

In terms of values, we propose that legal education and competency assessments of lawyers include fostering an understanding of law as a normative practice, including the specific values which tend to be reproduced by the legal profession as well as those potentially opposing values which may emphasize access to justice on a principled basis. In other words, competent lawyers must be able to critically assess the values in legal systems and legal education, and to measure the capacity of law and lawyers to promote substantive equality. In addition, self-reflexivity in terms of one's individual position (for example, as a beneficiary of settler colonialism) should be treated as central to lawyer competency, rather than as an optional or marginalized elective component of education and certification. The legal profession trades on expertise, specialization, and the privileging of certain forms of knowledge, as well as control of information. Based on our study, we propose that competent lawyers must be aware of their own limits, not only in terms of specific legal knowledge, but in terms of their role as a single factor among many components in the life of a client or community. We see this as a form of cultural humility, ${ }^{38}$ which specifically requires taking account of the limits of legal roles and expertise as well as recognizing the infinite forms of expertise which exist beyond Euro-settler law.

\section{Toward Competencies for Access to Justice}

Our research calls into question the efficacy of generic, technocratic taxonomies of skills, supporting Harry Arthurs' concern that 'making graduating students tick all the boxes on an arbitrary list of 'competencies' and fields of substantive law is no way to ensure they will be 'practice ready' today, much less that they will stay that way for the rest of their careers." ${ }^{\prime 39}$ Specifically, the observations of the community members and community legal advocates in our two studies underscore the contextuality, relationality, and cultural specificity of lawyering practice, and suggest that lawyers seeking to improve access to justice require the support of communities that they serve. In addition, the competencies and approaches to practice set out by the respondents in our research studies necessarily require investments of time and commitment by lawyers: this underscores the need for investment in community-engaged and community-responsive legal aid programs and clinics. While a detailed discussion of the various approaches to legal aid in Canada is beyond the scope of this article, we do believe that the community clinic model is best suited to being the site of the kinds of approaches to legal practice set out in this article. ${ }^{40}$ Furthermore, in terms of increasing lawyers' capacity to understand context and to build relationships, law schools and law societies should consider the benefit of both diverse admissions and the integration of practitioners' own lived experience as facets of improving competencies and creating meaningful interaction with diverse communities. This may require specific resistance to the cultural

38 Tervalon and Murray-Garcia explain that cultural humility involves "a lifelong commitment to self-evaluation and selfcritique, to redressing the power imbalances... and to developing mutually beneficial and non-paternalistic clinical and advocacy partnerships with communities on behalf of individuals and defined populations: M Tervalon \& J MurrayGarcia, "Cultural Humility versus Cultural Competence: A Critical Distinction in Defining Physician Training Outcomes in Multicultural Education" (1998) 9 J Health Care Poor Underserved 117 at 117.

39 Arthurs, supra note 15 at 5.

40 See Lenny Abramowicz, "The Critical Characteristics of Community Legal Aid Clinics in Ontario" (2004) 19 J L \& Soc Pol'y 70 for an overview of the characteristics of community legal clinics. 
features of law school and practice that require "leaving one's self at the door" in law schools. ${ }^{41}$ Finally, as discussed above, our studies are small in scale and there is a clear need for broader in-depth empirical studies on lawyer competencies in Canada: We urge researchers to take up this task, and we recommend the following methodological considerations for larger scale research:

- future studies should not assume a pregiven set of competencies, but should rather seek to determine from the data how competencies should be defined and providing evidence-based justification for these conclusions;

- while surveys may form a part of larger studies, we suggest that such research should not be limited to surveys, but should use in-person interviews and focus groups;

- where feasible, self-reported data should be corroborated with observation based methodologies;

- study cohorts should include not only lawyers but clients, representatives of community-serving agencies, legal educators, law students, and government service providers;

- study cohorts should be diverse in terms of geography, urban/rural divisions, income level, race, Indigeneity, gender, culture, sexual orientation, age, and disability, building in extra measures to ensure representation from those traditionally marginalized in discussions of the legal profession;

- for any work in which the researchers seek to make conclusions responding to particular goals, such as access to justice, that the people most impacted by those goals be included as central respondents at all stages of research and dissemination.

41 Duncan Kennedy, Legal Education and the Reproduction of Hierarchy: A Polemic Against the System, (New York: NYU Press, 2007) 